\title{
Narrativas de Alunas-Professoras dos Anos Iniciais do Ensino Fundamental: uma cultura de aula de matemática
}

\author{
Student-Teachers' Narratives of Primary School: a culture of the \\ mathematics classroom
}

Reginaldo Fernando Carneiro*

\begin{abstract}
Resumo
Este artigo tem como objetivo discutir a cultura de aula de Matemática presente em narrativas sobre as lembranças relacionadas à Matemática durante a vida escolar de nove alunas-professoras de um curso a distância de Pedagogia. Para tanto, realizamos uma pesquisa de natureza qualitativa, que utilizou, para a produção de dados, uma atividade do curso que se referia a escrita de uma narrativa. A análise dos dados evidenciou que a cultura de aula de Matemática evocada pelas lembranças pautava-se na reprodução, ou seja, na memorização e na aplicação mecânica de fórmulas, algoritmos e procedimentos; que as aulas eram expositivas e os conteúdos matemáticos enfatizados eram os números e as operações; e que a relação professor-aluno era perpassada por experiências positivas e negativas, pois alguns professores se destacaram pela compreensão dos alunos, pelo gosto em ensinar e outros, pelos castigos e pelas humilhações.
\end{abstract}

Palavras-chave: Narrativa. Formação de Professores. Ensino de Matemática.

\begin{abstract}
This article aims to discuss the culture of mathematics classroom present in narratives about the memories related to mathematics during the school life of nine student-teachers of a Pedagogy distance course. Therefore, we conducted a qualitative research, which we used to produce data, an activity of the course that meant writing a narrative. Data analysis showed that the culture of the mathematics classroom is guided in reproduction, memorization, and mechanical application of formulas, algorithms and procedures. The lessons were expository and numbers and operations were the mathematical content emphasized; and the teacher-student relationship was pervaded by positive and negative experiences, because some teachers stood out due to students' understanding, happiness to teach, and other punishments and humiliations.
\end{abstract}

Keywords: Narrative. Teacher Education. Mathematics Teaching.

\footnotetext{
* Doutor em Educação pela Universidade Federal de São Carlos - UFSCar. Professor do Núcleo de Educação em Ciências, Matemática e Tecnologia da Faculdade de Educação da Universidade Federal de Juiz de Fora - UFJF, Juiz de Fora, MG, Brasil. Endereço para correspondência: Rua Padre Anchieta, 17, apto 203, São Mateus, CEP: 36016-440, Juiz de Fora, MG, Brasil. E-mail: reginaldo.carneiro@ufjf.edu.br.
} 


\section{Introdução}

Este artigo, recorte da pesquisa de doutorado do autor, tem como objetivo discutir a cultura de aula de Matemática presente em narrativas sobre as lembranças relacionadas à Matemática durante a vida escolar de nove alunas-professoras - Alice, Ana, Andréia, Branca, Kerusca, Lusmarina, Maria Clara, Renata e Su - de um curso a distância de Pedagogia. Elas foram denominadas de alunas-professoras, pois eram alunas do curso a distância e já atuavam como professoras nos Anos Iniciais do Ensino Fundamental.

As narrativas foram utilizadas, neste artigo, como ferramenta tanto de formação como de pesquisa, e as práticas de ensino de Matemática e a relação professor-aluno nelas presentes foram tomadas como foco para discutir a cultura de aula de Matemática.

Conseguimos apreender esses aspectos a partir da primeira atividade virtual proposta na disciplina de Linguagens: Matemática 1 , que se referia à escrita de uma narrativa orientada pelos seguintes questionamentos: Qual era o seu sentimento em relação à Matemática?; Como se processava o ensino (ou as aulas) de Matemática?; Quais as principais facilidades ou dificuldades que você tinha para aprender Matemática?; Que temas ou áreas da Matemática você aprendia mais facilmente?; Que temas ou áreas da Matemática apresentavam maior dificuldade de aprendizagem para você?; Como eram as tarefas nas aulas de Matemática?; Como eram as lições de casa de Matemática?; Como eram as avaliações?; Você se lembra de alguma situação de ensino da Matemática que o tenha marcado positivamente ou negativamente?; Existe algum professor de Matemática que tenha marcado a sua vida (positiva ou negativamente)? Por quê?

A escrita de narrativas pode possibilitar aos seus autores conhecerem-se a si mesmos e, como destacado por Josso (2010), refletirem sobre como me tornei no que sou e como tenho as ideias que tenho. Dessa forma, permite a "tomada de consciência de significados novos e enriquecedores para a compreensão de si próprios ou do ambiente que os rodeia" (JOSSO, 2010, p. 71). Essa reflexão sobre como aprenderam Matemática e sobre seus sentimentos em relação a essa disciplina possibilitou às alunas-professoras a tomada de consciência das barreiras, das limitações e dos entraves que podem estar presentes quando ensinam Matemática e que podem dificultar a aprendizagem dos alunos.

Sabemos que não há aí uma relação de causa e efeito, ou seja, tomar consciência das marcas negativas que alguns professores de Matemática deixaram em suas vidas, não causa 
mudança imediatana prática docente. Mas é um processo em que, a partir de reflexões, podese também mudar a prática de sala de aula. Portanto, refletir sobre a docência e escrever a seu respeito é o primeiro passo para que as alunas-professoras enfrentem essas dificuldades.

Para Souza e Cordeiro (2007, p. 47), os sujeitos, ao escreverem narrativas, fazem emergir lembranças, histórias e representações sobre aprendizagens, discursos e rituais pedagógicos. Assim, essa escrita "[...] torna possível desvendar modelos e princípios que estruturam discursos pedagógicos que compõem o agir e o pensar docente e rever cristalizações sobre a prática", pois permite reconstruir experiências e refletir sobre seu próprio percurso formativo.

A partir das narrativas das alunas-professoras, tomamos conhecimento de que, durante suas vidas escolares, o ensino e a aprendizagem dessa disciplina basearam-se na reprodução. A consciência dessas crenças, que podem ter sido incorporadas às suas práticas de sala de aula, é o primeiro passo na busca de rupturas.

Nessa mesma perspectiva, para Cunha (1997, p. 3), a escrita de narrativas pode possibilitar que o sujeito descubra os significados que atribuiu aos fatos que vivenciou e reconstruaa compreensão que tem de si mesmo. "Ao mesmo tempo em que o sujeito organiza suas ideias para o relato, ele reconstrói sua experiência de forma reflexiva e, portanto, acaba fazendo uma autoanálise que lhe cria novas bases de compreensão de sua própria prática”.

Górriz (2008) propõe, a partir de um modelo de investigação/formação autobiográfica, a discussão de algumas dimensões que permitem ao sujeito a reconstrução de si mesmo. Algumas delas fazem parte do processo de elaboração de narrativas:

a) Dimensão experiencial: a vida é composta por diversas ações e experiências cotidianas que compõem as vivências, as sensações e as emoções. As experiências mais marcantes são aquelas que o sujeito resgata na escrita das narrativas e que são fontes de conhecimento, autoconhecimento, elaborações teóricas e de formação.

b) Dimensão introspectiva: a busca introspectiva de nossas recordações, vivências e experiências dá a possibilidade de "olhar, observar, reviver, captar, explorar, narrar, compreender e interpretar nosso mundo interior" (GÓRRIZ, 2008, p. 308).

c) Dimensão emocional: ao reviver as experiências para expressá-las na escrita, emergem sentimentos e emoções como a dor, a alegria, a tristeza, entre outros, o que indica o quanto aquela experiência foi marcante e significativa para o sujeito. 
d) Dimensão existencial: de acordo com a autora (2008, p. 308), "elaborar a experiência nos permite descobrir nossa existencialidade, a maneira pela qual nos sentimos, atuamos e nos posicionamos no mundo".

e) Dimensão psicossocial: ao reviver as experiências, a introspecção leva o sujeito a conhecer a si mesmo e a conhecer o modelo psicossociológico interior, ou seja, seus valores, atitudes, ações etc. e, dessa forma, pode compreender suas ações e tomar decisão para mudálas ou melhorá-las.

f) Dimensão investigadora/cognitiva: a indagação sobre a vida conduz à descoberta e, para tanto, requer a curiosidade para saber "quem somos, que experiências significativas marcaram e modelaram nossa vida, de onde viemos e para onde vamos. Exige recolher informação precisa, concreta e exaustiva para descrevê-la, narrá-la, compreendê-la, analisá-la, interpretá-la e criar teorias e conhecimento social, pessoal e científico" (GÓRRIZ, 2008, p. 309).

Compreendemos que essas dimensões estão imbricadas e fazem parte do processo de escrita de narrativas. Assim, ao recordarem como era ou como ainda é a relação com a Matemática, com seu ensino e sua aprendizagem, as alunas-professoras fizeram emergir os sentimentos, as práticas e a relação professor-aluno. A importância desse processo está na possível percepção dos aspectos do ensino e da aprendizagem da Matemática - como, por exemplo, o foco na memorização dos algoritmos das operações fundamentais - que, durante sua vida escolar não se pautaram na compreensão dos processos implícitos.

A dimensão experiencial é fundamental na reflexão das lembranças das alunasprofessoras sobre a Matemática, pois são essas experiências marcantes, muitas vezes de forma negativa, que influenciam a prática docente. Mas é a partir das dimensões introspectiva e existencial que elas podem interpretar o como me tornei no que sou e como tenho as ideias que tenho, na busca pela compreensão dessas experiências, ou seja, podem entender quais seus sentimentos e porque atuam de determinada forma. São ainda permeadas pela dimensão emocional, que faz emergir, muitas vezes, com relação à Matemática, sentimentos de medo, de angústia, de incompreensão etc.

A dimensão psicossocial leva-as a conhecerem-se melhor e a tomarem consciência de suas ações, o que pode ocasionar mudanças no sentido de melhorar o ensino de Matemática para seus alunos. Por outro lado, a dimensão investigadora/cognitiva possibilita a elaboração de teorias para explicar essas ações. 
Destacamos que as quatro primeiras dimensões são importantes, porque possibilitam emergir experiências marcantes, sentimentos com relação à Matemática e compreender suas razões. Por outro lado, as duas últimas dimensões são potencializadoras de mudanças, a partir das ações e da elaboração de teorias explicativas para elas.

Com base nessas considerações, inicialmente, apresentaremos a fundamentação teórica, fazendo uma discussão sobre a cultura de aula de Matemática. Depois, traremos os caminhos percorridos para o desenvolvimento do estudo. Em seguida, exporemos e analisaremos os dados referentes à cultura de aula de matemática e, por fim, faremos algumas considerações.

\section{Fundamentação teórica}

Neste artigo, apropriamo-nos do conceito de Viñao Frago (1998, p. 168-169) de cultura escolar: "conjunto de teorias, princípios ou critérios, normas e práticas sedimentadas ao longo do tempo no interior das instituições educativas". São modos de pensar e atuar, de forma a integrar-se à vida cotidiana da escola.

$\mathrm{Na}$ perspectiva desse autor, a cultura escolar é institucional e institucionalizada, porque se produz dentro das instituições docentes e do sistema educativo e se oferece como um conjunto de ideias, pautas e práticas consolidadas. Assim, os "aspectos organizativos e institucionais contribuem a conformar um ou outro modo de pensar e atuar e, ao mesmo tempo, estes modos conformam as instituições de um ou outro sentido" (VIÑAO FRAGO, 1998, p. 174).

Nesse contexto, consideramos cultura de aula de Matemática o modelo que vem sendo construído historicamente, tem sido arraigado, impregnado à cultura escolar e está presente na formação escolar do professor que ensina Matemática (CEZARI; GRANDO, 2008).

A partir dessa definição, Cezari e Grando (2008) destacam que, via de regra, a cultura de aula de Matemática está pautada no modelo de aprendizagem que enfatiza o treino de técnicas de memorização, em que os professores reproduzem as práticas com que tiveram contato durante sua escolarização. Além disso, as experiências negativas com relação a seus professores de Matemática emergem na forma de trauma, medo e angústia que podem se manifestar no ensino dos conteúdos matemáticos. 
Nesse sentido, Chacón (2000) ressalta que há uma relação cíclica entre o afeto ${ }^{1}$ e a aprendizagem da Matemática: por um lado, a experiência dos estudantes, ao aprender Matemática, provoca diferentes reações e influencia na formação das crenças e, por outro, suas crenças têm consequências diretas no comportamento, em situações de aprendizagem, e em sua capacidade para aprender.

Essas crenças vão sendo construídas pela observação (LORTIE, 2002), ao longo de seus processos de aprendizagem e, portanto, desde o início da escolarização, e podem perdurar até a formação inicial na universidade. Se não houver tomada de consciência, discussão, reflexão, compreensão e problematização, com o intuito de perceber os percalços e os obstáculos que essas crenças podem impor ao processo de ensino-aprendizagem da Matemática, esses mesmos sentimentos apresentados pelas alunas-professoras poderão ser transmitidos aos seus alunos.

Chacón (2000, p. 25) discute alguns aspectos relativos às consequências do afeto na aprendizagem da Matemática. Esse sentimento tem um poderoso impacto no modo como os alunos aprendem e utilizam a Matemática; estabelece o contexto pessoal dentro do qual funcionam os recursos, as estratégias heurísticas e o controle no trabalho com a Matemática; influencia na estrutura do autoconceito como aprendiz de Matemática, pois os estudantes que têm crenças rígidas e negativas acerca da Matemática e de sua aprendizagem, pois "normalmente são aprendizes passivos e, na aprendizagem, dão mais ênfase à memorização que à compreensão".

Essa autora (2000) explicita que o afeto em relação à Matemática pode ser considerado como sistema regulador, indicador, força de inércia e veículo do conhecimento matemático. $\mathrm{O}$ afeto forma um sistema regulador do conhecimento matemático do aluno, no sentido de nortear como ele atua, pensa e orienta sua execução. Dessa forma, se o estudante compreende a Matemática como cálculo, quando lhe são propostas atividades que exigem raciocínio, podem advir sentimentos como medo, angústia, desânimo etc. e, inclusive, o desejo de desistir rapidamente de tentar resolver a atividade. Assim, as dificuldades de aprendizagem são inerentes às crenças que o aluno tem acerca da Matemática e de si mesmo.

Por isso, Chacón (2000, p. 27) acrescenta que os estudantes atuam sob uma forte rede de influências e que

${ }^{1}$ Chacón (2000) inclui, no domínio afetivo, as crenças, as atitudes e as emoções. 
os professores de matemática, os alunos, pais, têm sua perspectiva de matemática e de seu ensino e aprendizagem. Essas crenças afetam as crenças do aprendiz e usualmente nem sempre na mesma direção. A tomada de consciência da atividade emocional é um instrumento de controle pessoal, um poderoso mediador das relações com os outros e um elemento chave na autorregulação da aprendizagem na sala de aula.

O afeto também pode se constituir como um indicador das aprendizagens matemáticas, pois a partir de sua perspectiva de Matemática e de suas crenças pode-se ter uma ideia das experiências que teve com relação ao ensino-aprendizagem da Matemática.

Pode ainda o afeto atuar como força de inércia, ou seja, ele pode fazer com que os professores sejam resistentes a mudanças. Assim, se o docente entende que a melhor forma de ensinar Matemática é trabalhar com algoritmos e fórmulas, seu ensino estará centrado nesses aspectos e será muito difícil fazer com que ele trabalhe em outra perspectiva.

Por fim, o afeto pode ser um veículo do conhecimento matemático, no qual o professor pode pautar-se para buscar respostas às dificuldades enfrentadas pelos alunos na aprendizagem de um conteúdo, pois, segundo Chacón (2000), elas podem ter origem nas atitudes dos estudantes em relação à Matemática, à linguagem, à notação matemática e à forma como aprendem.

Retomando a discussão sobre a cultura de aula de Matemática, Cezari e Grando (2008, p. 92, grifo das autoras) explicitam que

a aula de matemática, como um dos espaços de aprendizagem matemática, reforça
um modelo de ensino-aprendizagem que considera o aluno como um recipiente que
armazena informações, cabendo ao professor, essencialmente, transmitir
corretamente as informações e proporcionar tarefas ou mesmo exercícios repetitivos
para que os alunos treinem uma habilidade adquirida, como a resolução de equações
e/ou aplicação de algoritmos. Essas técnicas necessitam ser memorizadas e
reproduzidas em provas, mas que quase nada contribuem para a avaliação da
compreensão dos alunos sobre os conceitos matemáticos.

O estudo dessas autoras evidenciou que os professores, durante sua trajetória escolar como alunos, tiveram contato com uma cultura de aula de matemática que enfatizava a memorização e a repetição de técnicas. Por isso, reproduziam, em sua prática docente, esses valores e crenças.

Para os professores, seus alunos não são capazes de aprender Matemática devido à incompreensão do texto matemático; à falta de estudo e de motivação para envolver-se com as atividades propostas; e à própria natureza do conhecimento matemático, que é exato, abstrato, exige rigor e formalidade e pode ser dominadoapenas pelos gênios (CEZARI; GRANDO, 2008). 
Compreendemos que investigar essa cultura de aula de Matemática por meio de narrativas das alunas-professoras, de suas lembranças com relação à Matemática durante a escolarização pode contribuir para a reflexão, em busca de mudanças nessa cultura de aula de Matemática.

\section{Caminhos da pesquisa}

Segundo Fiorentini e Lorenzato (2006, p. 60), a pesquisa é "um processo de estudo que consiste na busca disciplinada/metódica de saberes ou compreensões acerca de um fenômeno, problema ou questão da realidade ou presente na literatura o qual inquieta/instiga o pesquisador perante o que se sabe ou diz a respeito". Para tanto, com o objetivo de discutir a cultura de aula de Matemática presente em narrativas sobre as lembranças relacionadas à Matemática na vida escolar das alunas-professoras, optamos pela abordagem qualitativa (BOGDAN; BIKLEN, 1994; LÜDKE; ANDRÉ, 1986).

Nesse contexto, fizemos um primeiro contato por e-mail com os 152 estudantes que ingressaram em 2007 no curso a distância de Pedagogia, para verificar sua possibilidade e disponibilidade para participar da pesquisa. Eles, na época, já haviam cursado a primeira oferta da disciplina de Linguagens: Matemática 1, de abril a maio de 2010, e estavam participando também da primeira oferta de Linguagens: Matemática 2, para o período de setembro a outubro de 2010. Recebemos o retorno de 61 estudantes que demonstraram interesse em participar da investigação.

Depois da autorização pelo Comitê de Ética da Universidade, procedemos ao envio, por e-mail, de questionários para a caracterização dos participantes que haviam respondido à mensagem inicial. Nesse questionário constavam perguntas sobre a formação dos estudantes, sua atuação profissional, e, caso fossem docentes, sobre a rede de ensino em que atuavam, carga horária e tempo de experiência. Recebemos o retorno de 32 questionários, nos quais identificamos que nove participantes já atuavam como docentes nos Anos Iniciais do Ensino Fundamental.

Selecionamos, para participação nesta investigação, apenas professoras que ensinavam conteúdos matemáticos em sala de aula e eram licenciandas no curso de Pedagogia. Elas escolheram o nome pelo qual seriam identificadas na pesquisa - algumas preferiram um nome fictício e outras optaram pelo seu próprio nome: Alice, Ana, Andréia, Branca, Kerusca, 
Lusmarina, Maria Clara, Renata e Su. Como já explicitamos, aqui nos referimos a elas como alunas-professoras, pois eram estudantes do curso e já atuavam como docentes.

Neste estudo, foi utilizada como fonte de dados a narrativa elaborada pelas alunasprofessoras na primeira atividade virtual de Linguagens: Matemática 1, disciplina que tem como objetivo discutir aspectos teóricos e metodológicos relacionados à Matemática.

Neste artigo, como já esclarecemos anteriormente, as narrativas foram utilizadas como ferramenta tanto de formação como de pesquisa. Na formação, as narrativas possibilitaram que as alunas-professoras fizessem emergir sua relação com a Matemática durante sua trajetória escolar,refletissem e tomassem consciência das dificuldades para ensinar Matemática.

$\mathrm{Na}$ pesquisa, foram utilizadas como fonte para a produção de dados. Segundo Cunha (1997, p. 2), as narrativas são representações da realidade e, por isso, cheias de significados e reinterpretações. Assim, "quando uma pessoa relata os fatos vividos por ela mesma, percebese que reconstrói a trajetória percorrida dando-lhe novos significados"; por isso, a narrativa revela a representação que o sujeito faz desses fatos e que pode promover a transformação da própria realidade.

Ainda de acordo com Cunha (1997, p. 7), as pesquisas que utilizam narrativas são, ao mesmo tempo, investigação e formação, e há uma relação dialética entre a teoria e a realidade. Essa autora, baseada nas ideias de Minayo, explicita que "ao mesmo tempo em que a realidade informa a teoria, esta, por sua vez, a antecede e permite percebê-la, reformulá-la, dar conta dela, num processo sem fim de distanciamento e aproximação".

Nesse contexto, a pesquisa com narrativas foi uma rica ferramenta de produção de dados que nos permitiu adentrar os sentimentos e as relações das alunas-professoras com a Matemática.

Com base nessas considerações, apresentaremos e discutiremos os dados das narrativas que evidenciam uma cultura de aula de Matemática, a partir de dois aspectos: as práticas de ensino de Matemática e a relação professor-aluno.

\section{Cultura de aula de Matemática na perspectiva das alunas-professoras}

Algumas práticas de ensino de Matemática foram ressaltadas pelas alunas-professoras nas narrativas sobre suas trajetórias escolares: o exercício de decorar a tabuada; a 
mecanização de fórmulas e algoritmos; a ênfase no ensino dos números e da aritmética; a resolução de exercícios.

As alunas-professoras destacaram que, quando alunas, tiveram que decorar a tabuada. Branca se recordou exatamente de um dos momentos em que a professora estava tomando a tabuada e ela contava em seus dedos. Su descreveu que havia chamada oral e a lição de casa escrever a tabuada do 2 até o 10 - devia ser realizada em cadernos próprios.

Uma coisa que me recordo certinho, inclusive parece que estou me vendo agora, é a professora tomando a tabuada, que por sinal era decorada, e eu grudada na lousa com as mãos para trás contando nos dedos... rs. É como se um filme passasse em minha cabeça. Jogos, nem pensar! Nada ajudava aprender a tabuada, era só decorando senão... (Branca, Narrativa, LM1, grifo da aluna-professora).

A professora exigia decorar a tabuada para resolver as divisões e multiplicações. A professora passava para casa todos os dias tabuada do 2 ao 10, onde tinha um caderno específico para realizar a tabuada que era vistado todos os dias e várias contas de multiplicação e divisão e toda sexta-feira tinha chamada oral da tabuada (Su, Narrativa, LM1).

Kerusca indicou que não conseguia entender a tabuada porque a multiplicação era diferente da adição e isso não era explicado pelo professor. "Para aprender tabuada (decorar) foi um desastre, eu não entendia o processo, porque 5x6=30 e 5+6=11? E a resposta era porque era multiplicação e não adição" (Narrativa, LM1).

As alunas-professoras relataram também que os algoritmos eram ensinados de forma mecânica, sem compreensão. Lusmarina revelou que tinha curiosidade para compreender o processo de solução do algoritmo da subtração com reserva.

Outra lembrança que tenho, era a minha curiosidade sobre as subtrações com reservas, naquela época aprendi que emprestávamos da dezena do minuendo e pagávamos na dezena do subtraendo, e me lembro de ficar pensando o porquê daquilo, mas não tinha coragem de perguntar à professora (Narrativa, LM1).

Kerusca afirmou que não teve problemas para aprender a adição e a subtração sem reservas, mas achou muito difícil essas operações com reserva. "Quando fui aprender adição com reserva e subtração com 'vamos emprestar', achei muito dificil. E pensa que a professora ensinava de outro jeito? Ou aprendia, ou aprendia" (Narrativa, LM1).

Su não conseguiu compreender o processo de resolução dos algoritmos e destacou que suas "dificuldades eram porque os professores nunca mostravam como realmente se chegava ao resultado. Tudo era mecânico, nunca entendia como realizar essas contas seguindo uma lógica" (Narrativa, LM1). 
Com relação aos conteúdos ensinados, era dada ênfase aos números e às operações aritméticas. Foram apontados por Kerusca, Renata e Su o ensino de conteúdos envolvendo os números e as atividades propostas com eles.

As tarefas sempre eram as mesmas, escrever números de 0 a 50, de 50 a 100, em ordem crescente, decrescente, de dois em dois, de três em três, e assim sucessivamente, principalmente quando fomos aprender a tabuada (Kerusca, Narrativa, LM1).

[...] consistia em escrever os numerais, começando do zero, "escreva como se lê" (a professora dizia que era importante saber como se escrevia, para que pudéssemos preencher cheques quando crescêssemos) (Renata, Narrativa, LM1).

As minhas recordações das aulas de matemática nas séries iniciais eram aprender a sequência dos números, ordem crescente e decrescente, números pares e ímpares. Lembro-me muito bem que a professora da $4^{a}$ série passava muitas continhas de adição, subtração, multiplicação e divisão (Su, Narrativa, LM1).

A aluna-professora Lusmarina indicou que teve dificuldades com as expressões numéricas: “A lembrança desse período mais nítida em minha memória é sobre as famosas expressões propostas na quarta série, tive dificuldade para resolver essas expressões enormes que tinham vários agrupamentos" (Narrativa, LM1).

As avaliações de Matemática eram sempre a reprodução de exercícios exatamente iguais àqueles resolvidos em sala de aula, havendo apenas a alteração dos números. Ana destacou que "[...] as avaliações eram a reprodução do que tínhamos escrito no caderno. Geralmente caíam os mesmos exercícios feitos na sala de aula" (Narrativa, LM1). Nesse mesmo sentido, Su apontou que "decorava a sequência em que eram resolvidas as atividades em sala de aula e aplicava nas atividades da prova, porque, a maioria das vezes, o professor só trocava os números da atividade, mas eram resolvidos da mesma forma que passava na sala de aula" (Narrativa, LM1).

As tarefas eram baseadas na resolução das operações fundamentais, realizadas " $n a$ maioria das vezes na quantidade [das letras] do alfabeto, ou seja, de A a Z, e os problemas que não exigiam muito raciocínio" (Maria Clara, Narrativa, LM1).

Enfatizando que as propostas tinham seu foco nos números e nas operações, em detrimento de outras áreas da Matemática, Maria Clara explicitou que sua "dificuldade em matemática era a geometria, que até a oitava série não foi ensinada com a devida importância. Eram raras as aulas que envolviam o estudo da geometria" (Narrativa, LM1). 
A aluna-professora Renata mencionou que o ensino de Matemática era fragmentado, pois, quando estudou desenho geométrico, não conseguia relacionar esse conteúdo à Matemática. "Lembro que na sétima e oitava série tinha a disciplina de Desenho Geométrico e adorava fazer os cálculos para desenhar os ângulos, as circunferências, os paralelogramos, mas na época não fazia ligação com a matemática, para mim eram coisas separadas" (Narrativa, LM1).

Renata ainda destacou que só conseguia resolver os problemas porque era informada qual a operação que devia realizar: "Lembro que lia os problemas que eram passados e não conseguia entender, mas, como era dito qual era a operação, eu fazia com facilidade" (Narrativa, LM1).

Além dos conteúdos, Ana apontou que, via de regra, o ensino era expositivo. Assim, o professor explicava o conteúdo e era solicitada aos alunos a reprodução exatamente igual à forma como lhes fora ensinado. Em suas palavras: “o ensino de matemática no Ensino Fundamental I era na maioria das vezes oral (expositivo), ou seja, a professora explicava o conteúdo e a gente o reproduzia do mesmo modo como ela o ensinava" (Narrativa, LM1).

Observamos, pelos trechos, que as práticas enraizadas nas aulas de Matemática enfatizavam a memorização de técnicas e fórmulas. Assim, havia, na escolarização das alunas-professoras, uma cultura de aula de Matemática que valorizava a reprodução, em detrimento da compreensão dos conceitos matemáticos. Tal cultura está pautada na visão tecnicista (FIORENTINI, 1995), que determina decorar tabuada, fórmulas, algoritmos e procedimentos, para serem reproduzidos nos exercícios e também nas avaliações. Essa tendência surgiu no Brasil em meados da década de 1970 e reduziu a Matemática a um conjunto de técnicas, regras, algoritmos e procedimentos, sem a preocupação de justificá-los ou fundamentá-los. Enfatiza o fazer, em detrimento da compreensão, da análise, da justificativa, da demonstração.

De acordo com Fiorentini (1995, p. 17), esse tipo de aprendizagem consiste "no desenvolvimento de habilidades e atitudes e na fixação de conceitos ou princípios" a partir de atividades que estimulem a memorização de fatos e o desenvolvimento dessas habilidades e atitudes.

Desse modo, o ensino não é centrado nem no professor, nem no aluno, mas nos objetivos instrucionais, nos recursos e nas técnicas de ensino. Para o autor, "os conteúdos tendem a ser encarados como informações, regras, macetes ou princípios organizados 
logicamente e psicologicamente por especialistas" (FIORENTINI, 1995, p. 18), e o professor e o aluno ocupam uma posição secundária, de meros executores.

Assim, como explicitado por Fiorentini (1995), a reprodução mecânica é mais importante que a compreensão dos conceitos matemáticos, por isso, Ana indicou que teve "facilidade para entender conceitos matemáticos, decorar fórmulas, as tabuadas, mas interpretar as situações-problema mais difíceis em alguma fase da minha vida foi bem complicado" (Narrativa, LM1).

Para atingir os objetivos estabelecidos, os alunos tinham que copiar muitas vezes a tabuada e reproduzir os exercícios exatamente como eles lhes haviam sido ensinados. $\mathrm{O}$ ensino era expositivo e enfatizava os números e as operações aritméticas, deixando em segundo plano outras áreas da Matemática, como a geometria, por exemplo.

Essa perspectiva de ensino de Matemática é denominada por Lima (1998, p. 99 e p. 98) de pedagogia do treinamento. Os professores explicam o conteúdo, resolvem alguns exemplos na lousa, propõem que os alunos façam uma enorme lista de exercícios e depois, na avaliação - que normalmente é uma prova escrita -, reproduzam esse conteúdo exatamente da mesma forma. Esses quatro momentos - mostrar o conceito, mostrar seu funcionamento, treinar e avaliar - fazem parte dessa pedagogia, que é caracterizada pela aprendizagem do saber fazer, que, "por não implicar pensamento, acontece simplesmente pela manipulação das regras da operacionalidade do conceito, do treinamento no mecanismo algorítmico". Segundo esse autor, essa concepção enfatiza o saber fazer operacional, em detrimento do saber pensar conceitual, implicando "a contra-aprendizagem matemática, na sua substituição por uma ação de condicionamento".

Nesse contexto, essa tendência tecnicista, embasada na reprodução, não possibilita a formação de indivíduos pensantes, críticos e reflexivos, para viverem na sociedade atual.

As discussões apresentadas remetem-nos à maneira como é organizada a sala de aula, pois isso pode trazer implícita essa visão tecnicista de Matemática, como destaca Viñao Frago (1998, p. 175): "a análise histórica das modalidades de organização e disposição de pessoas e objetos na sala de aula, mostra sua relação com o sistema ou método pedagógico seguido".

Na perspectiva da Matemática pautada nessa visão, em que se enfatiza a reprodução, a memorização de fórmulas e algoritmos; em que as aulas são, via de regra, fundamentadas na exposição dos conteúdos pelo professor, a organização da sala de aula coloca os estudantes sentados individualmente e um atrás do outro. Essa forma de organização, com a qual as 
alunas-professoras tiveram contato em suas trajetórias escolares, é empregada porque, para que os alunos aprendam, é necessário apenas que ouçam as explicações do professor e fiquem em silêncio.

O silêncio e a atenção exigidos não aconteceriam, por exemplo, se os alunos estivessem trabalhando em grupos, em que conversam, trocam ideias, buscam argumentar sobre suas estratégias para a resolução de uma atividade. Esse burburinho, naquela perspectiva apontada, é sinal de indisciplina e, portanto, deve ser evitado a todo custo.

As alunas-professoras também trouxeram relatos sobre seus professores que, de alguma forma, deixaram marcas em sua trajetória escolar - algumas positivas e outras negativas.

Seis participantes da pesquisa relataram terem sido marcadas positivamente por seus professores. Alice comentou sobre um docente, no Ensino Médio, e lamentou não ter aproveitado melhor seus ensinamentos, porque, segundo ela, ele foi um de seus melhores professores.

No segundo colegial, tive um professor com uma história de vida muito bonita, até os dezoito anos era analfabeto e tratador de cavalos, começou a estudar fez faculdade e trabalhava na rede estadual e particular, foi um dos meus melhores professores, hoje sinto por não ter aproveitado tudo o que ele nos ensinou e sua dinâmica (Narrativa, LM1).

Andréia e Kerusca citaram brevemente professores com quem elas consideram ter aprendido muito, pois eles conseguiam entender os estudantes. Kerusca assim se referiu à professora Ângela: "Eu tive uma professora fabulosa, Angela, que explicava tanto até espumar os cantos da boca. Ela me acompanhou até a $8^{a}$ série e me ensinou muito". Nas palavras de Andréia: “O meu professor de matemática do CEFAMㄹ foi que mais me marcou, pelo gosto que tinha em ensinar e pela compreensão das dificuldades dos alunos; infelizmente não me recordo o nome" (Narrativa, LM1).

Renata descreveu um professor de Geografia que a surpreendeu, pois, em suas aulas, ensinou uma forma de calcular a longitude e a latitude. Para Renata, não era possível outra disciplina utilizar a Matemática: "Na $8^{a}$ série, tive um professor de geografia que me fez ver a matemática em outra disciplina, quando começou a ensinar contas com longitudes e

\footnotetext{
${ }^{2}$ Centro Específico de Formação e Aperfeiçoamento do Magistério.
} 
latitudes. Lembro que fiquei, com minhas colegas, indignada, pois, como pode geografia ter matemática no meio!?!” (Narrativa, LM1).

Maria Clara explicitou que sempre gostou de Matemática, nunca teve dificuldade e, por ser boa aluna e tirar boas notas, sua professora a tornou uma espécie de auxiliar que a ajudava em suas necessidades.

Sempre gostei de matemática e por esse motivo nunca tive muitas dificuldades no seu aprendizado. [...] Recordo mais precisamente da quarta série do ensino fundamental. Eu era o xodó da professora que hoje vejo erradamente, me fazia de sua ajudante em todas as necessidades. Nas atividades de matemática só tirava A. Além do capricho e a organização dos cadernos era boa nas continhas e problemas (Narrativa, LM1, grifo da aluna-professora).

Interessante observar que os professores lembrados de forma positiva são destacados por compreenderem os alunos, pelo gosto em ensinar e até pela história de vida. A relação professor-aluno se baseia principalmente no afeto, nos sentimentos e nas emoções e, com exceção de Kerusca, as outras participantes não se recordam de um docente pelo fato de ele ensinar bem Matemática, por exemplo. Isso demonstra a importância do tipo de relação criado entre educador e educando, pois ela pode influenciar os alunos de forma tanto positiva como negativa.

Três participantes narraram experiências desagradáveis com professores. Lusmarina comentou que, ao iniciar seus estudos, já com o ano letivo em andamento, o medo da professora fez com que não sanasse suas dúvidas. "Tive muita dificuldade com o conteúdo que estava sendo dado. Logo fiquei muito receosa, porque a professora era muito brava e, como já estava adiantado o conteúdo, não conseguia entender e tinha medo de perguntar". (Narrativa, LM1).

A aluna-professora ainda recordou que tivera um professor muito rigoroso, que provocava muito medo nos alunos, principalmente quando ele os chamava para resolver exercícios na lousa e dizia, de antemão, que eles errariam. Esse medo fez com que ela se dedicasse muito mais aos estudos para que, quando fosse solicitada sua ida ao quadro, pudesse acertar a resolução.

Tive a decepção de ter um professor de matemática um pouco mais rigoroso e que era temido por todos, devido a sua falta de educação e mesmo o medo que incutia em seus alunos, só faltava nos espancar para que fosse pior; e, por incrível que pareça, foi de raiva da maneira desse professor ser, que comecei a me interessar mais pela matemática e, consequentemente, aprender mais. Como ele nos fazia ir à lousa e já dizia de antemão que iríamos errar, comecei a querer acertar para poder confrontá-lo 
e assim fui uma dos seis alunos aprovados direto naquele ano e acabei por me apaixonar pela matemática (Narrativa, LM1).

Alice comentou sobre sua professora da $6^{\mathrm{a}}$ série, que era autoritária e castigava os estudantes que erravam a solução do exercício que faziam na lousa. "A professora era autoritária e tinha uns métodos militares, íamos todos os dias à lousa, e deveríamos falar passo a passo a realização dos exercícios e, quando errávamos, ela nos chamava de polentas azedas e enfiava umas unhas enormes nas nossas costas" (Narrativa, LM1).

Maria Clara descreveu sua professora da $5^{\text {a }}$ série, que era muito brava e também castigava os alunos, além de humilhar aqueles que não tiravam boas notas nas provas.

Recordo-me do que ela fazia com o restante da sala. Todos tinham que resolver atividades na lousa e, quando erravam, ela puxava as orelhas. [...] Quando fazíamos as avaliações, na hora de entregar as notas, ela colocava o lixinho da sala perto da sua mesa, chamava o aluno e, se fosse nota vermelha ( $D$ e E), ela jogava a prova no lixo. O aluno, muito envergonhado, pegava sua prova no lixo, às vezes até amassada. Era um horror (Narrativa, LM1).

A aluna-professora Maria Clara também narrou outro episódio, em que um professor do Ensino Médio, logo no início do ano, para conhecer os seus novos alunos, perguntava-lhes de qual escola eles eram oriundos, quem havia sido seu professor no Ensino Fundamental e, conforme as respostas, ele os qualificava como bons ou maus em matemática. Para mostrar que ele estava certo, ele mandava os estudantes resolverem exercícios na lousa.

Estávamos começando os estudos da matemática e o professor, oralmente, queria conhecer os alunos: de qual escola estavam vindo e quem tinha sido o professor. Então começou pelos alunos do Dantés (escola em que eu tinha estudado) e foi passando na lousa perguntas variadas e, na minha vez, talvez por nervosismo, pois ele já havia dito que os alunos do Dantés não sabiam nada de matemática porque a professora era ruim, errei. Fiquei muito envergonhada e ele confirmou sua tese, dizendo que ele teria muito trabalho comigo e com os outros da professora Onélia (minha professora de matemática que me ensinou muito) (Narrativa, LM1).

Os excertos apresentados trazem situações muito fortes, que causam impacto e, até mesmo, chocam, pois, sem dúvida, causaram muito medo e angústia nas alunas-professoras durante suas trajetórias escolares. Esses castigos e humilhações que vivenciaram passaram a fazer parte da representação de Matemática, pois, de acordo com Viñao Frago (1998, p. 179), as práticas ou pautas do comportamento formam o núcleo da cultura escolar e esta se constitui “dos modos de atuar que, sedimentados ao longo do tempo, são adotados e interiorizados de 
um modo automático, não reflexivo, pelos professores e alunos". Então, nos questionamos: como gostar de Matemática ou se interessar pela escola com esses castigos e humilhações?

São questões importantes, porque, de acordo com Chacón (2000), há uma forte relação entre as emoções, as crenças, as atitudes e a aprendizagem da Matemática. Há uma implicação mútua, ou seja, as experiências com a aprendizagem da Matemática influenciam na formação das crenças, das emoções e das atitudes, assim como o afeto pode ter implicações na capacidade de aprender. Da mesma forma, essas emoções, crenças e atitudes influenciam na forma como esses professores ensinam Matemática.

Além disso, na perspectiva de Tardif e Lessard (2008, p. 19), o trabalho docente é uma profissão de interações humanas. $\mathrm{O}$ trabalho interativo é aquele que tem o ser humano como seu objeto e sua principal característica é "colocar em relação, no quadro de uma organização (escola, hospitais, serviços sociais, prisões, etc.), um trabalhador e um ser humano que se utiliza de seus serviços". Nesse cenário, as pessoas são a matéria-prima do processo de trabalho, que tem como finalidade manter, mudar ou melhorar a situação humana das pessoas e também do próprio trabalhador que com elas opera.

Segundo esses autores (2008), o trabalho docente se constitui das interações humanas que ocorrem entre professores e alunos em vários contextos e, especialmente, na sala de aula e é, portanto, o fundamento das relações sociais na escola.

Como se pôde observar, a relação das alunas-professoras com seus professores foi permeada por sentimentos positivos, como o gosto em ensinar, a história de vida do docente, a insistência em explicar um conteúdo até que o aluno o entendesse, a compreensão da dificuldade dos estudantes. Mas também foi pontilhada por sentimentos de medo, de angústia, de sofrimento a que as alunas foram submetidas, mesmo que indiretamente. Situações de constrangimento e humilhação, quando professores autoritários castigavam os alunos ou os expunham à turma, solicitando-lhes irem à lousa para resolver uma atividade. Assim, as interações professor-alunos foram marcadas por diferentes aspectos, que vão além do ensino dos conteúdos matemáticos.

Tardif e Lessard (2008) ressaltam que os alunos são seres sociais e, por isso, despertam reações, intervenções, atitudes que são representações sociais construídas a partir de fontes e que orientam a prática docente. Esse fato leva o professor a fazer escolhas, colocar suas preferências e também imbuir-se de práticas pedagógicas diferentes. Nessa relação, 
também é fundamental a afetividade, que pode provocar o gosto pela Matemática; ou a sua ausência, traumas e aversão.

Compreendemos que esses aspectos fazem o movimento da sala de aula e há uma inter-relação entre eles, no sentido de guiar e direcionar as interações que ocorrem todos os dias, desde o momento em que o professor entra na escola. Nesse sentido, a vivência entre alunos e professor pode determinar o gosto, o interesse e a motivação em aprender a Matemática ou o surgimento de sentimentos negativos com relação a essa disciplina, que podem permanecer por toda a vida.

No relacionamento educador-educando, de acordo com Morales (1999), o professor pode ter a intenção primeira de ensinar os conteúdos de sua disciplina, mas sua fala, seus gestos, suas atitudes, seus valores, que ele coloca em foco, mesmo inconscientemente, em suas aulas, serão aprendizagens, muitas vezes, mais significativas e permanentes para seus alunos.

Pode ocorrer um ensino não intencional por parte do professor e uma aprendizagem não consciente, o que pode provocar nos alunos a aquisição de valores e atitudes positivas ou negativas; e que se dá pelo que "somos, pela maneira de nos apresentar, com nosso estilo de relacionamento e atitude geral com relação aos alunos, com os comentários individuais, com o modo pelo qual lidamos com situação de conflito" (MORALES, 1999, p. 23).

Parece-nos que as lembranças que as participantes desta pesquisa guardam de seus professores trazem aspectos que se enquadram em aprendizagens não intencionalmente ensinadas por eles, pois, de acordo com Morales (1999, p. 25, grifos do autor), o professor pode "ensinar mais com o que é do que com aquilo que pretende ensinar; seu modo de fazer as coisas implica mensagens implícitas de efeitos que podem ser positivos ou negativos".

Dessa forma, como indicado nos excertos apresentados pelas alunas-professoras, os professores se tornam modelos a partir de suas atitudes, seus valores, sua forma de ensinar e da relação que mantêm com os alunos e isso pode ou desencadear o gosto pela Matemática ou cultivar medos e angústias, devido aos castigos e às humilhações.

Esse fato é muito sério e merece destaque para evidenciar o cuidado que o professor deve ter nessa relação, pois ele é o adulto, o profissional formado para atuar nesse contexto tão complexo que é a sala de aula e a vida das crianças que estão sob sua responsabilidade pode ser profundamente afetada por suas atitudes e seus valores. 


\section{Algumas considerações}

Neste artigo, tivemos como objetivo discutir a cultura de aula de Matemática presente em narrativas das lembranças relacionadas à Matemática durante a vida escolar de nove alunas-professoras de um curso a distância de Pedagogia.

A cultura de aula de Matemática está pautada no paradigma tecnicista, que se justifica pela memorização e pela aplicação mecânica de fórmulas e algoritmos. Por isso, em suas lembranças, as alunas-professoras explicitaram que o ensino de Matemática focava a memorização da tabuada, pela ênfase nos números e nas operações fundamentais.

Além disso, as tarefas consistiam em realizar uma grande quantidade de exercícios, com o intuito de treinar o aluno para repetir esse mesmo conteúdo na avaliação, que apresentava exercícios exatamente iguais aos resolvidos em sala de aula. Nesse sentido, as aulas eram expositivas: o professor expunha a definição, colocava alguns exemplos na lousa; os alunos resolviam exercícios e, por fim, era feita a avaliação.

Essa perspectiva não contempla a compreensão e a justificativa dos conceitos matemáticos ensinados, mas apenas a memorização e sua posterior reprodução. Para tanto, exigia-se silêncio durante a aula e a permanência dos estudantes sentados individualmente.

Ainda, a análise dos dados evidenciou que a relação professor-aluno pode ter implicações tanto positivas quanto negativas, pois experiências escolares em que os alunos são submetidos a castigos e humilhações podem provocar aversão, traumas, medos com relação à Matemática. Por outro lado, os considerados bons professores podem despertar o gosto pela disciplina.

Interessante ressaltar que os professores que marcaram de forma positiva as alunasprofessoras foram lembrados, via de regra, pelo gosto em ensinar, pela história de vida, pela compreensão com que tratavam os alunos, e não por ensinar bem Matemática, evidenciando que o professor é modelo para o aluno e suas atitudes podem ser aprendizagens permanentes. Assim, emoções, atitudes e crenças têm implicações nas aprendizagens de Matemática.

Consideramos que a relevância deste texto se encontra em fazer emergir, por meio da escrita de narrativas, esses aspectos de cultura de aula de Matemática arraigada em práticas engessadas de ensino de Matemática e na relação professor-aluno pautada em experiências negativas. Assim, os formadores podem levar os professores a refletirem, questionarem e 
problematizarem essas lembranças, de modo que consigam perceber que tais práticas podem ser obstáculos para sua futura prática docente.

Portanto, é fundamental que o formador promova intervenções, para que o sentido dado pelo autor da narrativa às aprendizagens possibilite que ele se conscientize, de forma a adquirir poder sobre esse sentido (CHIENÉ, 2010, p. 132), pois, "se o formador torna possível que o autor da formação seja também autor de um discurso sobre a sua formação, este último terá acesso, pela sua palavra, ao sentido que dá à sua formação e, mais ainda, a si próprio".

\section{Referências}

BOGDAN, R. C.; BIKLEN, S. K. Investigação qualitativa em educação: uma introdução à teoria e aos métodos. Porto: Porto Editora, 1994. 336p.

CEZARI, V. G. F.; GRANDO, Regina C. Cultura de aula de matemática presente nas narrativas de formação por professores do ensino fundamental. Horizontes, Itatiba, v. 26, n. 1, p. 89-96, jan./jun. 2008.

CHACÓN, I. M. G. Matemática emocional: los afectos en el aprendizaje matemático. Madrid: Narcea, 2000. 276p.

CHIENÉ, A. A narrativa de formação e a formação de formadores. In: NÓVOA, Antônio; FINGER, M. (Org.). O método (auto)biográfico e a formação. Natal: EDUFRN, 2010. p. 129-142.

CUNHA, M. I. Conta-me agora! As narrativas como alternativas na pesquisa e no ensino. Revista da Faculdade de Educação, São Paulo, v. 23, n. 1-2, 1997. Disponível em:

<http://www.scielo.br/scielo.php?script=sci_arttext\&pid=S0102-25551997000100010\# 1 aut $>$. Acesso em: 20 maio 2008.

FIORENTINI, D. Alguns modos de ver e conceber o ensino da matemática no Brasil. Zetetiké, Campinas, v. 3, n. 4, p. 1-37, nov. 1995.

FIORENTINI, D.; LORENZATO, S. Investigação em educação matemática: percursos teóricos e metodológicos. Campinas: Autores associados, 2006. 226p.

GÓRRIZ, I. L. A autobiografia como modelo formativo/educativo de bem-estar e transformação socioexistencial. In: PASSEGI, M.C.; SOUZA, E. C. (Org.). (Auto)biografia: formação, territórios e saberes. Natal: EDUFRN, 2008. p. 301-316.

JOSSO, M. C. Da formação do sujeito... Ao sujeito da formação. In: NÓVOA, A.; FINGER, M. (Org.). O método (auto)biográfico e a formação. Natal: EDUFRN, 2010. p. 59-79.

LIMA, L. C. Da mecânica do pensamento ao pensamento emancipado da mecânica. In: PROGRAMA INTEGRAR.Caderno do Professor: trabalho e tecnologia. CUT/SP, 1998. p. 95-103.

LORTIE, D. C. Schoolteacher: a sociological study. Chicago: The University of Chicago Press, 2002. $284 p$. 
LÜDKE, M.; ANDRÉ, M. E. D. A. Pesquisa em educação: abordagens qualitativas. São Paulo: EPU, 1986. 99p.

MORALES, P. A relação professor-aluno: o que é, como se faz. São Paulo: Loyola, 1999. 169p.

SOUZA, E. C.; CORDEIRO, V. M. R. Por entre escritas, diários e registros de formação. Presente! Revista de Educação, Salvador, n. 57, p. 45-49, 2007.

TARDIF, M.; LESSARD, C. O trabalho docente: elementos para uma teoria da docência como profissão de interações humanas. Petrópolis: Vozes, 2008. 317p.

VIÑAO FRAGO, A. Por una historia de la cultura escolar: enfoques, cuestiones, fuentes. In: CONGRESO DE LA ASOCIACIÓN DE HISTORIA CONTEMPORÁNEA, 3., 1998, Valladolid España. Anais... Valladolid - España, 1998, p. 167-183. Disponível em:

<http://www.ahistcon.org/docs/Valladolid.pdf>. Acesso em: 11 ago. 2012.

Submetido em Agosto de 2013. Aprovado em Janeiro de 2014. 